Research article

\title{
Proteotypic classification of spontaneous and transgenic mammary neoplasms
}

\author{
Igor Mikaelian, Natalie Blades, Gary A Churchill, Karen Fancher, Barbara B Knowles, \\ Janan T Eppig and John P Sundberg
}

The Jackson Laboratory, Bar Harbor, Maine, USA

Corresponding author: Igor Mikaelian, igor.mikaelian@roche.com

Received: 26 May 2004 Revisions requested: 9 Jul 2004 Revisions received: 16 Jul 2004 Accepted: 9 Aug 2004 Published: 6 Oct 2004

Breast Cancer Res 2004, 6:R668-R679 (DOI 10.1186/bcr930)

(C) 2004 Mikaelian et al. licensee BioMed Central Ltd

This is an Open Access article distributed under the terms of the Creative Commons Attribution License (http://creativecommons.org/licenses/by/

2.0), which permits unrestricted use, distribution, and reproduction in any medium, provided the original work is cited.

\begin{abstract}
Introduction Mammary tumors in mice are categorized by using morphologic and architectural criteria. Immunolabeling for terminal differentiation markers was compared among a variety of mouse mammary neoplasms because expression of terminal differentiation markers, and especially of keratins, provides important information on the origin of neoplastic cells and their degree of differentiation.
\end{abstract}

Methods Expression patterns for terminal differentiation markers were used to characterize tumor types and to study tumor progression in transgenic mouse models of mammary neoplasia (mice overexpressing $\mathrm{Neu}$ (Erbb2), Hras, Myc, Notch4, SV4O-TAg, Tgfa, and Wnt1), in spontaneous mammary carcinomas, and in mammary neoplasms associated with infection by the mouse mammary tumor virus (MMTV).

Results On the basis of the expression of terminal differentiation markers, three types of neoplasm were identified: first, simple carcinomas composed exclusively of cells with a luminal phenotype are characteristic of neoplasms arising in mice transgenic for Neu, Hras, Myc, Notch4, and SV4O-TAg; second, 'complex carcinomas' displaying luminal and myoepithelial differentiation are characteristic of type $P$ tumors arising in mice transgenic for Wnt1, neoplasms arising in mice infected by the MMTV, and spontaneous adenosquamous carcinomas; and third, 'carcinomas with epithelial to mesenchymal transition (EMT)' are a characteristic feature of tumor progression in Hras-, Myc-, and SV4O-TAg-induced mammary neoplasms and PL/J and SJL/J mouse strains, and display de novo expression of myoepithelial and mesenchymal cell markers. In sharp contrast, EMT was not detected in papillary adenocarcinomas arising in BALB/cJ mice, spontaneous adenoacanthomas, neoplasms associated with MMTV-infection, or in neoplasms arising in mice transgenic for $\mathrm{Neu}$ and Wnt1.

Conclusions Immunohistochemical profiles of complex neoplasms are consistent with a stem cell origin, whereas simple carcinomas might originate from a cell committed to the luminal lineage. In addition, these results suggest that the initiating oncogenic events determine the morphologic features associated with cancer progression because EMT is observed only in certain types of neoplasm.

Keywords: cancer, epithelial to mesenchymal transition, keratin, mammary gland, neoplasia

\section{Introduction}

Architectural and cytological patterns have been the basis for mammary tumor categorization for more than a century [1]. Over the past 20 years, immunohistochemistry has added a molecular dimension to the categorization of mammary neoplasms: altered expression of oncogenes, oncosuppressor genes, hormone receptors, and cytoskeletal proteins have been identified as useful indicators of disease outcome. Gene microarray analysis has confirmed the importance of many of these histological prognosticators [2-4], which - in conjunction with clinical features such as lymph node status, tumor size, and tumor grade [5] - are undeniably useful. However, these prognosticators do not seem to be useful to identify the pathways that lead to tumorigenesis and cancer progression.

Transgenic mouse models of mammary cancer have added considerably to our knowledge of human breast 
tumorigenesis. More specifically, in addition to dissecting the molecular mechanisms underlying mammary development and the initial steps of mammary neoplastic transformation, mouse models have shown that activation of a particular pathway is reflected in specific histologic patterns $[6,7]$.

In view of the evidence that terminal differentiation markers are important pathway markers [7] and prognostic predictors $[4,8-10]$, we compared the expression of terminal differentiation markers and some morphologic features of spontaneous and transgene-induced mammary tumors in mice. This study corroborates molecular $[2,3,11-14]$ and immunohistochemical $[4,7,15]$ studies in human cancer patients and mouse models of human cancer recommending that, in addition to the broadly accepted and well-documented use of architectural features [6,7,16-19], diagnostic criteria should also take into account the cell types into which neoplastic cells differentiate.

We have identified neoplastic cells with luminal, myoepithelial, and mesenchymal phenotypes. Myoepithelial differentiation is 'constitutive' to specific tumor types, for example adenosquamous carcinomas, adenomyoepitheliomas, and adenocarcinomas associated with the active mouse mammary tumor virus (MMTV) and the wingless-related MMTV integration site $1(W n t 1)$ transgene. In contrast, in neoplasms dependent on the myelocytomatosis oncogene $(M y c)$, Harvey rat sarcoma viral oncogene 1 (Hras), and SV40 T antigen (SV4O-TAg) transgenes, myoepithelial differentiation is an important event in the specific type of tumor progression characterized by epithelial to mesenchymal transition (EMT). The occurrence in some transgenic models of distinct proteotypic expression patterns, defined as groups of neoplasms expressing a specific set of terminal differentiation markers, suggests an as yet unreported degree of variability in transgenic models, perhaps reflective of the diversity of second-hit mutations in these tumors. Finally, specific types of spontaneous mammary tumors are histologically and immunohistochemically indistinguishable from some of the transgene-induced mammary tumor models. This provides the background information to test the hypothesis that tumor phenotype is a predictor of tumor genotype.

\section{Methods \\ Mice}

The pathology database [20] of The Jackson Laboratory was searched from 1987 to 2001 for spontaneous mammary tumors in production and research colonies. Slides were reviewed and categorized on the basis of standardized criteria [17-19,21-23].

In addition, newborns of the following strains were obtained from The Jackson Laboratory Induced Mutant
Resource (Bar Harbor, ME): C57BL/6JTg(WapTAg)1 Knw, FVB/N-Tg(WapNotch4)10Rnc/J, B6SJL-Tg(Wnt1)1 Hev/J (hereafter abbreviated B6SJLWnt1), FVB/NJ-Tg(Wnt1)1Hev/J (hereafter abbreviated FVB-Wnt1), FVB/N-Tg(MMTVneu)202Mul/J, FVB/NTg(WapMyc)212Bri/J, FVB/N-Tg(WapHRAS)69LIn YSJL/J, and FVB/NJ-Tg(MMTVTGFA)254Rjc/J and B6D2$\mathrm{Tg}$ (MMTVTGFA)254Rjc/J. Mice were weaned at 3 weeks of age and genotyped by polymerase chain reaction. Detailed information on the genotyping protocols and breeding conditions are available online at http:// jaxmice.jax.org/info/index.html. These mice were aged until they developed mammary masses, which were fixed by immersion in Fekete's acid-alcohol-formalin. Slides were sectioned at 5-6 $\mu \mathrm{m}$ and stained with hematoxylin and eosin (H\&E).

\section{Immunohistochemistry}

Consecutive sections (5-6 $\mu \mathrm{m}$ thick) on Superfrost Plus slides (Fisher Scientific, Fair Lawn, NJ) of paraffin-embedded neoplasms were immunolabeled for $\alpha$-smooth muscle actin (SMA; Sigma, St Louis, MO), keratin 1 (KRT2-1, hereafter abbreviated K1; BabCo, Richmond, CA), keratin 5 (KRT2-5, hereafter abbreviated K5; BabCo), keratin 6 (KRT2-6, hereafter abbreviated K6; BabCo), keratin 10 (K1-10, hereafter abbreviated K10; Babco), keratin 13 (KRT13, hereafter abbreviated K13; Sigma), keratin 14 (KRT1-14, hereafter abbreviated K14; BabCo), keratin 17 (KRT1-17, hereafter abbreviated K17; PA Coulombe, The Johns Hopkins University, Baltimore, MD) [24], keratins 8/ 18 (KRT8 and KRT18, hereafter abbreviated K8/18; Progen, Heidelberg, Germany), vimentin (Biomeda, Foster City, CA), filaggrin (BabCo), involucrin (Babco), loricrin (Babco), and trichohyalin (T-T Sun, The New York University School of Medicine, New York, NY) as described previously [25]. All these antibodies were mouse-specific except the antibodies against $\mathrm{K} 13$, trichohyalin, and vimentin, which were raised against human proteins, the antibody against $\mathrm{K} 8 / 18$, which was raised against bovine keratins, and the antibody against SMA, which was raised against avian proteins. The anti-SMA antibody recognizes aortic $\alpha 2$ smooth muscle actin (ACTA2) and enteric $\gamma 2$ smooth muscle actin [26].

In brief, the method was as follows. Deparaffinized slides were gradually hydrated. Endogenous peroxidase activity was quenched by incubation with $3 \%$ hydrogen peroxide in methanol for $20 \mathrm{~min}$ at room temperature $\left(20-25^{\circ} \mathrm{C}\right)$. Heatmediated antigen retrieval in citrate buffer at $\mathrm{pH} 6.0$ was used for the antibodies targeted at K8/18 and vimentin. Slides were washed and were incubated for $30 \mathrm{~min}$ with blocking serum (10\% normal fetal calf serum diluted in phosphate-buffered saline). Excess blocking serum was blotted and the slides were incubated overnight at $4^{\circ} \mathrm{C}$ with primary antibodies diluted in phosphate-buffered saline. 
Secondary biotinylated anti-mouse or anti-rabbit antibody was applied for $30 \mathrm{~min}$ at room temperature, followed by incubation with the avidin-biotin complex (45 min). The reaction was developed with the substrate diaminobenzidine (Sigma) and the slides were counterstained with Mayer's hematoxylin. All spontaneous tumors were labeled for MMTV gp27 Gag, gp36 Env, and gp52 Env [27]. A mouse was identified as positive for MMTV if immunolabeling for at least one of the markers was detected in the tumor or nearby tissues.

Images were captured with a DP70 digital camera (Olympus, Melville, NY) on an Olympus BX41 microscope and color enhanced and balanced for contrast with Photoshop 6.0 (Adobe, San Jose, CA). Additional photomicrographs of H\&E-stained and immunolabeled slides are archived in the Mouse Tumor Biology Database, where they can be viewed on-line at http://tumor.informatics.jax.org [28].

\section{Slide interpretation and scoring of immunolabeling intensity}

Cell types were defined on the basis of a previous study that evaluated the expression of the same terminal differentiation markers in the developing mammary gland [29].

Expression of $\mathrm{K} 5, \mathrm{~K} 14, \mathrm{~K} 17$, and/or SMA was associated with a direct contact with a basement membrane and the morphology of a myoepithelial cell defined myoepithelial cell differentiation. Absence of labeling for any of the markers, or labeling for $\mathrm{K} 8 / 18$ along with a polygonal morphology, defined luminal cells.

Image analysis (Photoshop 6.0; Adobe, San Jose, CA) was used to evaluate the ratio of spindloid neoplastic cells on H\&E-stained sections on all tumors with EMT. EMT was considered significant when more than $1 \%$ of the neoplasm was composed of neoplastic cells having a spindloid to fusiform shape and blending into the stroma. These cells had an oval to elongated nucleus with less clumped chromatin than epithelial neoplastic cells. Their cytoplasm was more acidophilic than epithelial neoplastic cells.

Squamous differentiation was defined by the presence of one or more of the following features: the formation of a large core of cornified material, the formation of keratin pearls, the cornification of individual cells, or the presence of trichohyalin granules or keratohyalin granules. Squamous differentiation was confirmed by immunohistochemical expression of at least one of the following markers in the areas of squamous differentiation: $\mathrm{K} 1, \mathrm{~K} 6, \mathrm{~K} 10$, filaggrin, trichohyalin, involucrin, or loricrin, none of which is normally expressed in cycling mammary glands [29].

The intensity of immunolabeling was scored on a scale of 0 to 3 (immunolabeling levels: $0=$ none; $1=$ weak; $2=$ mod- erate; $3=$ intense). The grade for each cell type was the product of average labeling intensity and the relative percentage of cells $(0 \%, 0 ;$ up to $1 \%, 1 ; 2-5 \%, 2 ; 6-25 \%, 3$; $26-50 \%, 4$; more than $50 \%, 5)$ labeled at the predominant intensity. The outcome for each neoplasm was the sum of the grades for each cell type. If immunolabeling was detected in less than 10 cells in a tumor, the tumor was considered to be negative for this marker.

\section{Morphologic criteria}

All tumors were evaluated (presence/absence) on H\&Estained sections for myoepithelial differentiation, EMT, squamous differentiation, vascular invasion, proteinaceous or lipid droplets in neoplastic cells, and ductal differentiation (defined as tubular structures lined by a basal layer of cells with myoepithelial differentiation and a luminal layer of cuboidal cells). Type $\mathrm{P}$ tumors are neoplasms composed of a branching network of blind ducts lined by an epithelium at least two cells thick and terminated by structures resembling the terminal end buds of the pubertal mammary gland [7]. Macrocysts are large cysts lined by an epithelium one or two cells thick that occasionally forms small glands. Lactation-responsive plaques are discoid masses composed of contoured and anastomosed mammary acini at the periphery and ducts at the center.

\section{Results}

\section{Histologic tumor types (Table 1)}

Tumors were categorized histologically using the recommendations of the Mouse Models of Human Cancers Consortium categorization scheme [17-19] and the specific nomenclature applying to certain models [22] or tumor types $[21,23]$ when applicable.

Spontaneous tumors were papillary adenocarcinomas with papillae lined by a single layer of cells $(n=6$; Fig. 1), papillary adenocarcinomas with papillae lined by two layers of cells $(n=2$; Fig. 2), glandular adenocarcinomas with EMT $(n=4$; Fig. 3), microacinar adenocarcinomas in $\mathrm{C} 3 \mathrm{H} / \mathrm{HeJ}$ mice $(n=8$; Fig. 4), type $\mathrm{P}$ tumors in $\mathrm{C} 3 \mathrm{H} / \mathrm{HeJ}$ mice $(n=$ $3)$, adenomyoepitheliomas in BALBc/J mice $(n=5$; Fig. 5), and adenosquamous carcinomas ( $n=7$; Fig. 6$)$.

All Hras-induced ( $n=4 ;$ Fig. 7) and Neu-induced $(n=10)$ tumors as well as some Myc-induced ( $n=4$; Fig. $8 \mathrm{c}, 8 \mathrm{e}, 8 \mathrm{f}$ ) and SV40-TAg-induced tumors (data not shown) had a solid pattern. Some SV40-TAg-induced ( $n=5$; Fig. 9a,9b) and Myc-induced tumors ( $n=9$; Fig. $8 \mathrm{a}, 8 \mathrm{~b}, 8 \mathrm{~d}$ ) as well as all Notch4-induced tumors $(n=6)$ had a glandular pattern. Some Myc-induced ( $n=13$; Fig. 8), SV40-TAg-induced ( $n$ $=3$; Fig. 9), and Hras-induced $(n=3)$ carcinomas displayed areas of EMT. Some SV40-TAg-induced tumors ( $n$ $=4$ ) had a papillary pattern with papillae lined by epithelial cells that piled up in a disorderly fashion (data not shown). Preneoplastic lesions of Tgfa-transgenic mice consisted of 
Table 1

Proteotypic Classification of Spontaneous and Transgenic Mammary Neoplasms Based on Terminal Differentiation Markersa.

\begin{tabular}{|c|c|c|c|c|c|c|c|c|c|c|c|c|c|c|c|c|c|}
\hline Type & Strain/Transgene & Main patternc & $\begin{array}{l}\text { Myoepithelial } \\
\text { differentiation }^{d}\end{array}$ & EMT (\%)e & $\mathrm{K} 1$ & K5 & K6 & K8/18 & K10 & K14 & $\mathrm{K} 17$ & FLG & IVL & LOR & THH & SMA & VIM \\
\hline \multirow[t]{7}{*}{ Simple } & FVB-Myc & Glandular & $6 / 9$ & $4 / 9(<1 \%)$ & & + & + & + & & ++ & + & & & & & & \\
\hline & FVB-Notch4 & Glandular & $0 / 6$ & 0 & & & & + & & + & + & & & & & & \\
\hline & C57BL6/J-Tag & Glandular & $1 / 5$ & 0 & & & & + & & + & + & & & & & & \\
\hline & BALB/cJ (mostly) & Papillary, 1 cell thick & $2 / 6$ & 0 & & + & + & ++ & & ++ & ++ & & & & & & \\
\hline & C57BL6/J-Tag & Papillary & $0 / 4$ & 0 & & & & + & & + & + & & & & & & \\
\hline & FVB-Myc & Solid & $1 / 4$ & $3 / 4(<1 \%)$ & & & & + & & + & + & & & & & & \\
\hline & FVB-Neu & Solid & $0 / 10$ & 0 & & & & & & & & & & & & & \\
\hline \multirow[t]{9}{*}{ Complex } & $\mathrm{FVB}$ and B6D2-Tgfa & Macrocyst & $6 / 8$ & 0 & & + & + & +++ & & + & + & & & & & + & \\
\hline & $\mathrm{FVB}$ and B6D2-Tgfa & Lactation plaque & $3 / 3$ & 0 & & ++ & + & +++ & & ++ & + & & & & & + & \\
\hline & $\mathrm{BALB} / \mathrm{c} J$ & Adenomyoepithelioma & $5 / 5$ & 0 & + & +++ & ++ & ++ & & +++ & ++ & & & & & & \\
\hline & BALB/cJ (mostly) & Adenoacanthoma & $7 / 7$ & 0 & ++ & ++ & ++ & ++ & ++ & +++ & +++ & ++ & ++ & + & + & + & \\
\hline & СзH/HeJ & Microacinar & $8 / 8$ & 0 & & ++ & + & ++ & & ++ & + & & & & & & \\
\hline & $\mathrm{BALB} / \mathrm{cJ}, \mathrm{C} 3 \mathrm{H} / \mathrm{HeJ}$ & Papillary, 2 cells thick & $2 / 2$ & 0 & & ++ & & ++ & + & ++ & ++ & & & & & +++ & \\
\hline & $\mathrm{C} 3 \mathrm{H} / \mathrm{HeJ}$ & Type P tumor & $9 / 9$ & 0 & & ++ & + & ++ & & ++ & ++ & & + & & & +++ & \\
\hline & FVB-Wnt1 & Type $\mathrm{P}$ tumor & $6 / 6$ & 0 & & ++ & ++ & +++ & & ++ & ++ & + & + & & & ++ & \\
\hline & B6SJL-Wnt1 & Type $\mathrm{P}$ tumor & $7 / 7$ & 0 & & + & + & + & & ++ & + & & & & & ++ & \\
\hline \multirow[t]{4}{*}{ EMT } & C57BL6/J-Tag & Glandular with EMT & $2 / 3$ & $3 / 3(6 \%)$ & & & & +++ & & +++ & ++ & & & & & ++ & + \\
\hline & FVB-Myc & Glandular with EMT & $4 / 6$ & $6 / 6(20 \%)$ & & + & + & ++ & & ++ & ++ & & & & & + & + \\
\hline & $\mathrm{PL} / \mathrm{J}$ and SJL/J & Glandular with EMT & $4 / 4$ & $4 / 4(38 \%)$ & & ++ & + & +++ & & ++ & ++ & & + & & & ++ & ++ \\
\hline & FVB-Hras & Solid with EMT & $3 / 4$ & $3 / 4(<1 \%)$ & & + & & ++ & & + & + & & & & & & + \\
\hline
\end{tabular}

adata are coded, with "+++" representing highest grades; the intensity of immunolabeling was scored $0-3$ (immunolabeling levels: $0=$ none; $1=$ weak; $2=$ moderate; $3=$ intense); the grade for each cell type was the product of average labeling intensity and the relative percentage of cells $(0$ : $0 ; \leq 1 \%: 1 ; 2-5 \%: 2 ; 6-25 \%: 3 ; 26-50 \%: 4 ;>50 \%$ : 5) labeled at the predominant intensity; outcome for each neoplasm was the sum of the grades for each cell type and the data presented are the average for each group; white boxes indicate an average grade $<1 ; "+"$ indicates an average grade $\geq 1$ and $<5 ; "++"$ indicates an average grade $\geq 5$ and $<10 ; "+++"$ indicates an average grade $\geq 10$; EMT, epithelial to mesenchymal transition; FLG, filaggrin; IVL, involucrin; K1, keratin 1; K5, keratin 5; K6, keratin 6; K8/18, keratins 8 and 18; K10, keratin 10 ; K17, keratin 17; LOR, loricrin; THH, trichohyalin; SMA, $\alpha$-smooth muscle actin; VIM, vimentin.

bAbsence of information for the transgene indicates that the tumor arose in a non-transgenic mouse.

cBased on the recommendations of the Annapolis meeting [17-19].

dTumors with myoepithelial differentiation/tumors examined; carcinomas with minimal myoepithelial differentiation arising in mice transgenic for Myc were categorized as "simple carcinomas" because myoepithelial differentiation was interpreted as evidence of early EMT.

eTumors with EMT/ tumors examined; the data in parenthesis indicate the average percentage of the tumors comprised of neoplastic cells with a mesenchymal phenotype.

macrocysts ( $n=8$; Fig. $10 \mathrm{a}$ ) and lactation-responsive plaques ( $n=3$; Fig. 10b). All Wnt1-induced tumors $(n=$ 13; Fig. 11) exhibited a type $P$ tumor pattern.

All spontaneous type $\mathrm{P}$ tumors $(n=9)$, all microacinar carcinomas in $\mathrm{C} 3 \mathrm{H} / \mathrm{HeJ}$ mice $(n=8)$, and one of two papillary carcinomas in one $\mathrm{C} 3 \mathrm{H} / \mathrm{HeJ}$ mouse showed immunolabeling for MMTV (data not shown). Proteinaceous and/or lipid secretion was identified in a small number of tumors in most transgenic models and spontaneous tumor types (Fig. $2 a, 2 b)$, although it was observed most consistently in macrocysts and in adenosquamous carcinomas (Fig. $6 a, 6 c, 6 d, 6 e)$.

\section{Figure 1}

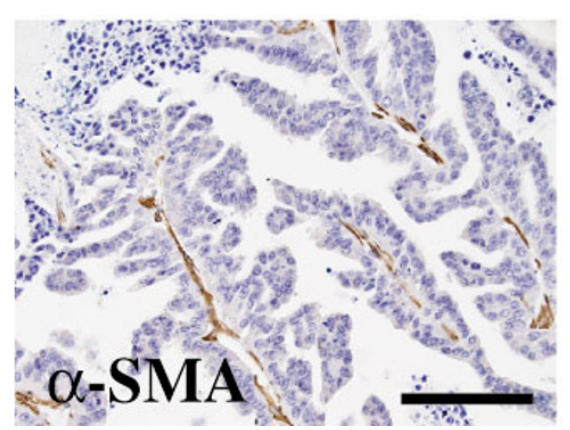

Papillary adenocarcinoma lined by an epithelium one cell thick in a BALB/cJ mouse: neoplastic cells lack myoepithelial differentiation. Myofibroblasts are present in the stroma of the neoplasm. Scale bar, 80 $\mu \mathrm{m}$. 

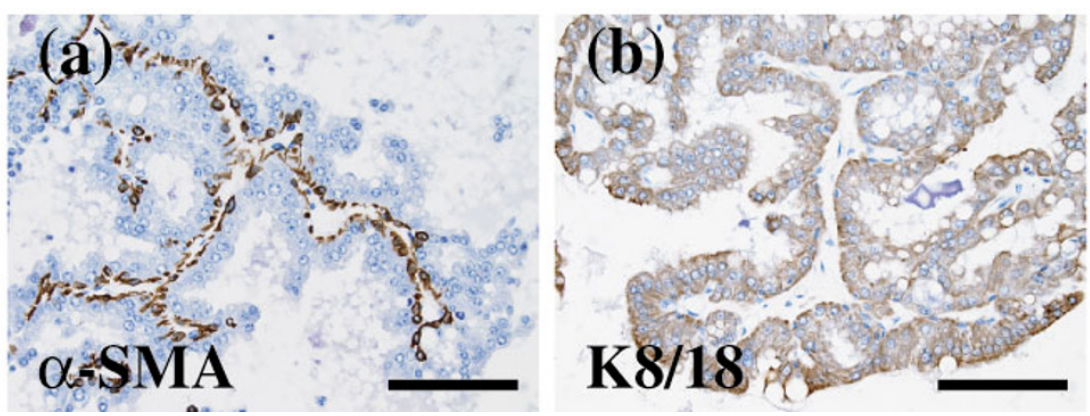

Papillary adenocarcinoma lined by an epithelium two cells thick: there is myoepithelial differentiation of the basal layer (a), whereas suprabasal cells have a luminal phenotype (b). Scale bar, $80 \mu \mathrm{m}$.

Figure 3

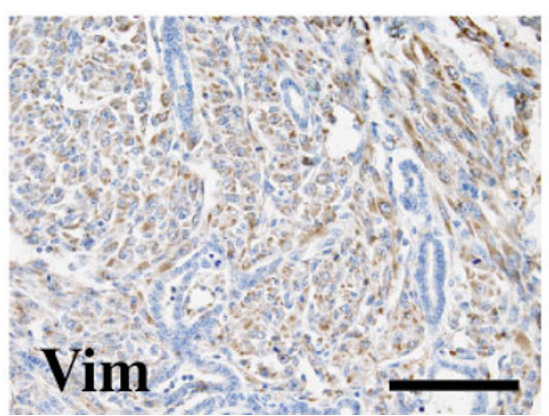

Epithelial to mesenchymal transition (EMT) in a spontaneous neoplasm: neoplastic cells with a spindloid phenotype are labeled strongly for vimentin in a glandular carcinoma with EMT in an SJL/J mouse. Scale bar, $80 \mu \mathrm{m}$

Figure 4

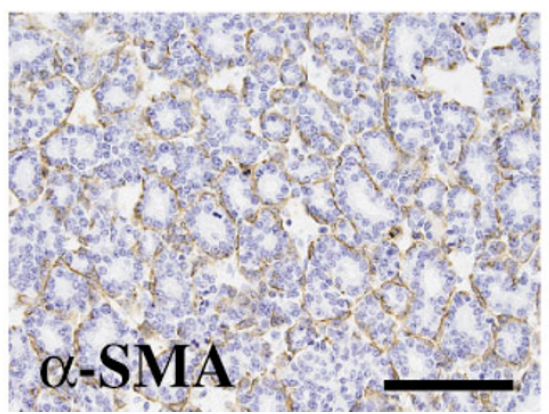

Microacinar carcinoma in a $\mathrm{C} 3 \mathrm{H} / \mathrm{HeJ}$ mouse infected by the mouse mammary tumor virus. Microacinar carcinomas are characterized by a microacinar pattern with prominent myoepithelial differentiation. Scale bar, $80 \mu \mathrm{m}$.

\section{Terminal differentiation proteins expression patterns}

The neoplasms were categorized into three groups: those with a pure luminal phenotype (simple carcinomas), those that constitutively expressed myoepithelial and luminal markers, and those that were characterized by EMT. Hampe and Misdorp [30] defined the term complex as 'any type of neoplasm or proliferation composed of cells resembling both secretory epithelial and myoepithelial cells'. We therefore used the term 'constitutively complex carcinomas' to indicate the tumors in which luminal and myoepithelial cells were arranged as they would be in a normal mammary gland, suggesting that these two types of cells originated from the same progenitor cell. The tumors that expressed myoepithelial markers in the areas of EMT only are designated 'acquired complex carcinomas' to indicate that myoepithelial differentiation was absent in the areas representing the original phenotype of the neoplasms, before the occurrence of EMT.

Tumor categorization was then redesigned to take into account not only the architecture of the neoplastic process [17-19] but also myoepithelial differentiation and EMT, which were not always apparent on $\mathrm{H} \& \mathrm{E}$-stained sections. Keratins 5,14 , and 17 , which are generally considered to be markers of myoepithelial cells [4], were occasionally identified in suprabasal cells in a variety of neoplasms (Figs $6 f, 6 h, 6 i, 8 c, 8 e, 8 f, 11 a)$. $\alpha$-Smooth muscle actin, another marker of myoepithelial cells, was expressed by suprabasal cells only in MMTV-associated and Wnt 1 -induced type $P$ tumors (Fig. 12c), a feature previously noted by $\mathrm{Li}$ and colleagues [13].

Neoplasms with a pure luminal phenotype (simple carcinomas) were identified in all transgenic models of mammary carcinogenesis (Fig. 7, Table 1) with the notable exception of Wnt1-induced carcinomas that had a constitutively complex phenotype. Most (six of nine) glandular carcinomas arising in mice transgenic for Myc showed a few areas of myoepithelial differentiation that were interpreted as early EMT rather than the neoplasms arising from a progenitor cell common to the luminal and myoepithelial phenotypes; hence these neoplasms with minimal myoepithelial 
Figure 5
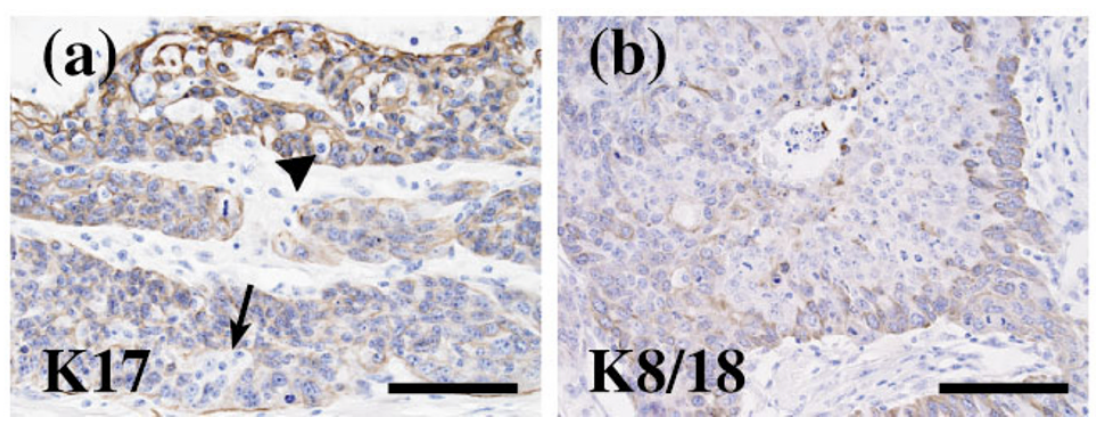

Adenomyoepithelioma in a BALB/cJ mouse: individual cells (a, arrowhead), clusters of cells (a, arrow), and occasionally large areas (b) are not labeled by antibodies against terminal differentiation markers of myoepithelial (a) and luminal cells (b) of the mammary gland. Scale bar, $80 \mu \mathrm{m}$.

Figure 6
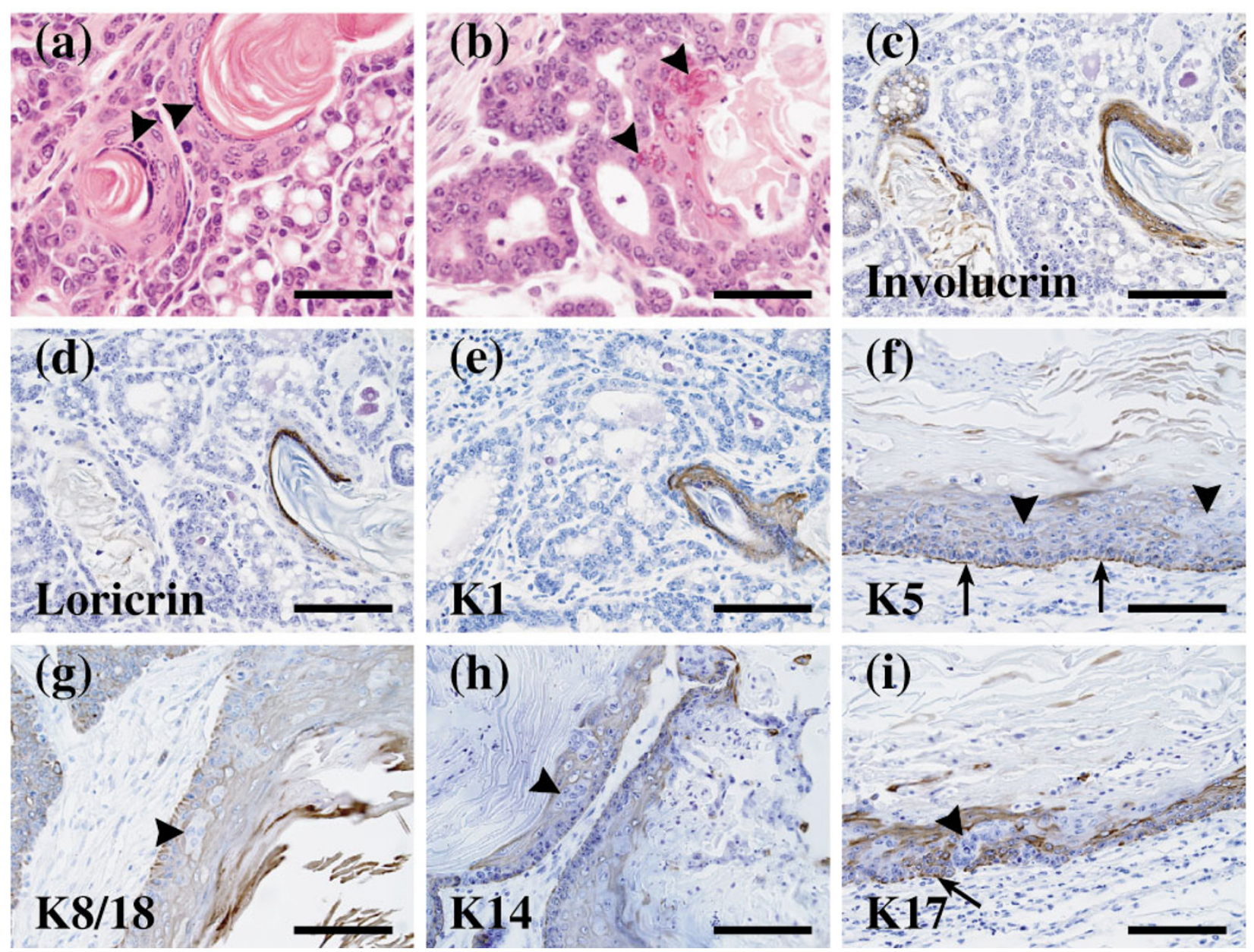

Adenosquamous carcinoma in a BALB/cJ mouse: squamous differentiation is commonly associated with the presence of keratohyalin (a, arrowhead) or trichohyalin (b, arrowhead) granules. Squamous differentiation is 'complete', with expression of markers of all layers of the epidermis (c-e). Individual cells and small clusters of cells fail to express, or express only weakly, any terminal differentiation marker ( $f-i$, arrowheads), whereas myoepithelial differentiation is observed in the areas of squamous differentiation ( $\mathrm{f}, \mathrm{i}$, arrows). Scale bars, $50 \mu \mathrm{m}(\mathrm{a}, \mathrm{b})$ and $80 \mu \mathrm{m}(\mathrm{c}-\mathrm{i})$. 
Figure 7

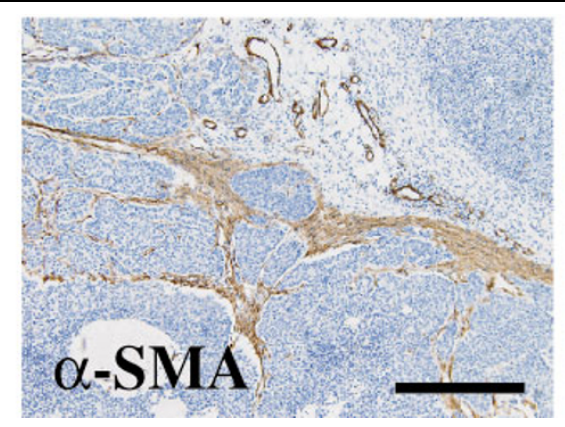

Solid carcinoma from a mouse transgenic for Hras: expression of $\alpha$ smooth muscle actin in carcinomas is restricted to stromal myofibroblasts and vascular smooth muscle fibers. A similar observation was made for carcinomas arising in mice transgenic for $\mathrm{Neu}$ (Erbb2) and Notch 4 and in most mice transgenic for SV40-TAg (not shown). Scale bar, $320 \mu \mathrm{m}$.

differentiation were categorized as 'simple' carcinomas. The only spontaneous neoplasms composed exclusively of cells with a luminal phenotype were four of six papillary carcinomas that, on H\&E sections, were characterized by papillae lined by an epithelium one cell thick.

Constitutively complex carcinomas consisted of spontaneous papillary carcinomas lined by an epithelium two cells thick (Fig. 2), microacinar adenocarcinomas arising in MMTV-infected C3H/HeJ mice (Fig. 4), type $\mathrm{P}$ tumors of MMTV-infected C3H/HeJ mice (Fig. 12) and Wnt1-transgenic mice (Fig. 11), adenomyoepitheliomas (Fig. 5), adenosquamous carcinomas (Fig. 6), and lactation-responsive plaques and most (six of eight) macrocysts of Tgfa-transgenic mice (Fig. 10). Neoplastic cells with a myoepithelial phenotype were abundant and formed an almost continuous layer surrounding cells with a luminal phenotype in microacinar carcinomas (Fig. 4) and in spontaneous papillary carcinomas lined by an epithelium two cells thick (Fig. 2a). In type P tumors, myoepithelial differentiation was most prominent in the areas of ductal metaplasia and was minimal or absent in the frond-like areas of the neoplasms (Fig. 12a). In adenosquamous carcinomas, myoepithelial differentiation was most prominent in the areas of squamous differentiation (Fig. 6f,6i), and was often absent in the glandular areas.

In adenomyoepitheliomas ( $n=5$ ), large proportions of suprabasal cells were labeled for $\mathrm{K} 5, \mathrm{~K} 6, \mathrm{~K} 8 / 18, \mathrm{~K} 14$, and $\mathrm{K} 17$, with $\mathrm{K} 1$ being expressed in only two tumors, and with duct formation and cornification being identified in four and three neoplasms, respectively. The morphology of neoplastic cells in adenomyoepitheliomas varied, ranging from fusiform to cuboidal. The proteotypic pattern of these cells is not characteristic of any specific cell type, and these cells were categorized as 'cells with myoepithelial differentiation' when in contact with a basement membrane and as 'luminal cells' when not in contact with a basement membrane. Neoplastic cells in adenomyoepitheliomas were difficult to differentiate from stromal myofibroblasts and, as reported earlier [31], they were negative for SMA.

In lactation-responsive plaques of Tgfa-transgenic mice, myoepithelial differentiation was most prominent in the areas of ductal differentiation located at the center of these lesions (Fig. 10b). The peripheral portions of lactationresponsive plaques, which morphologically resemble mammary acini, generally lacked myoepithelial differentiation. Macrocysts were predominantly composed of cells with a luminal phenotype (Table 1) that occasionally rested directly on the basement membrane. Segmental portions of six of eight macrocysts had myoepithelial cells (Fig. 10a).

Immunohistochemistry indicated that the descriptive term 'papillary carcinoma' encompasses a variety of neoplasms. First, most (four of six) spontaneous papillary carcinomas of BALB/cJ mice (Fig. 1) and all (four of four) papillary carcinomas with a pseudostratified epithelium in SV40-TAgtransgenic mice were exclusively composed of cells with a luminal phenotype (simple carcinomas). Cells with myoepithelial differentiation, identified in two of six spontaneous papillary carcinomas of BALB/cJ mice, were scarce and might represent entrapped remnants of the normal mammary gland, because they were located at the periphery of the neoplasm. In spontaneous papillary adenocarcinomas characterized by two layers of cells lining neoplastic papillae, the basal layer was continuous and had a myoepithelial phenotype (Fig. 2a), whereas cells of the luminal layer expressed K8/18 (Fig. 2b).

Type $\mathrm{P}$ tumors, adenomyoepitheliomas, and adenosquamous carcinomas were characterized by the presence of subpopulations of cells with a high mitotic index that did not express terminal differentiation markers, or expressed them only weakly. In type P tumors, these cells were grouped at the ends of the fronds, the morphology and immunohistochemistry of which mimicked terminal end buds of the pubertal mammary gland [29].

Adenomyoepitheliomas (Fig. 5a,5b) and adenosquamous carcinomas (Fig. 6f,6g,6h,6i) were populated by individual cells and clusters of cells with a large open-faced nucleus and a moderate amount of pale cytoplasm with the appearance of ground glass. These cells were haphazardly distributed in the solid areas of adenomyoepitheliomas and in the viable epithelium enclosing cornified debris in adenosquamous carcinomas. Similar populations of neoplastic cells with low expression of terminal differentiation markers were not detected in the other neoplasms. 
Figure 8

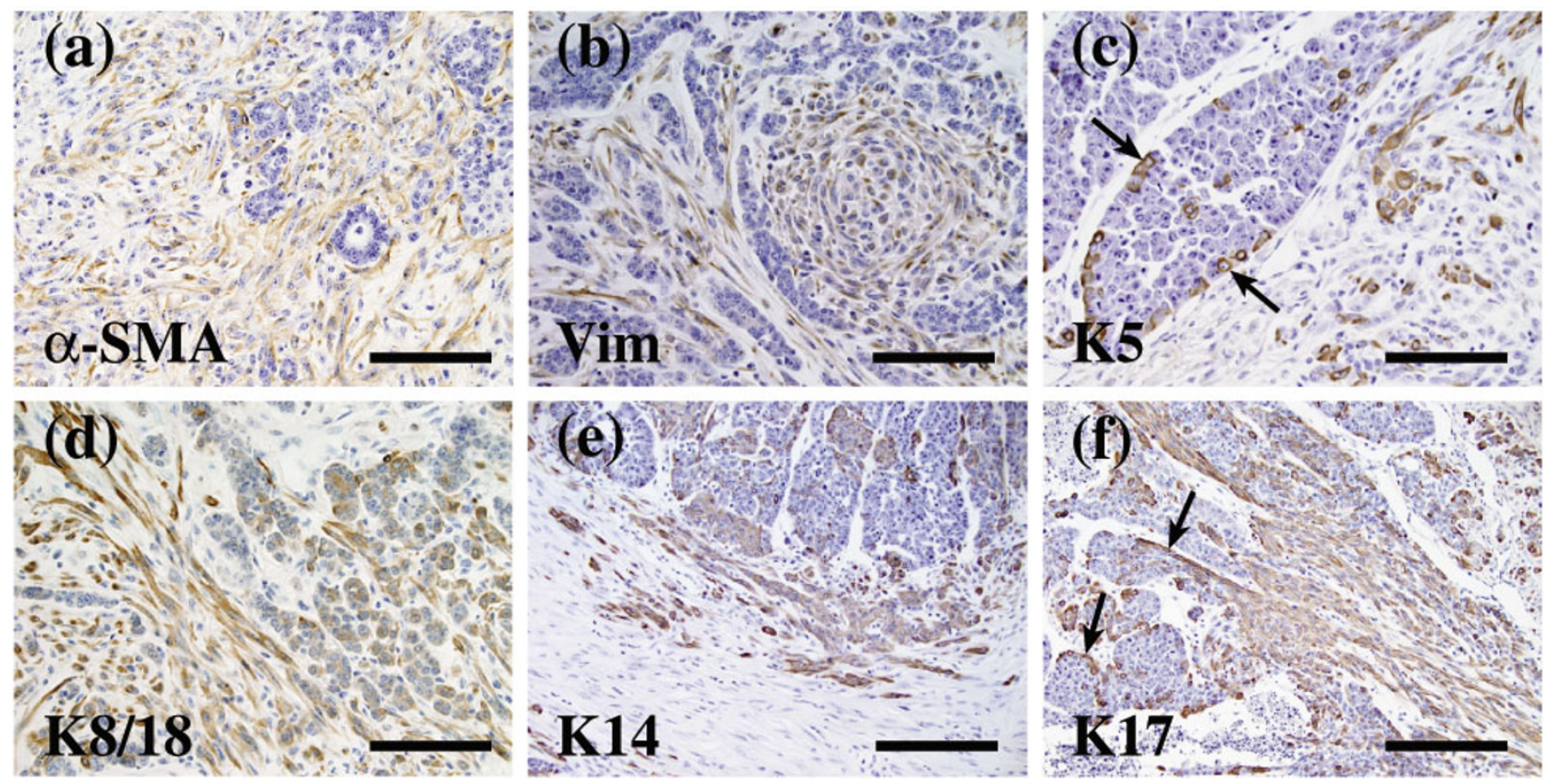

Epithelial to mesenchymal transition (EMT) in a mouse transgenic for Myc: EMT is associated with expression of terminal differentiation markers of mesenchymal (a,b), myoepithelial (c,e,f) and luminal (d) cells, with de novo acquisition of a myoepithelial phenotype (c,e,f, arrows) by neoplastic cells. Scale bars, $80 \mu \mathrm{m}(\mathrm{a}-\mathrm{d})$ and $160 \mu \mathrm{m}(\mathrm{e}, \mathrm{f})$. 'De novo' acquisition of the myoepithelial phenotype is defined as neoplastic cells displaying a myoepithelial phenotype in a portion of the neoplasm limited to the vicinity of the areas of EMT, whereas myoepithelial differentiation was lacking in the rest of the neoplasm (not shown).
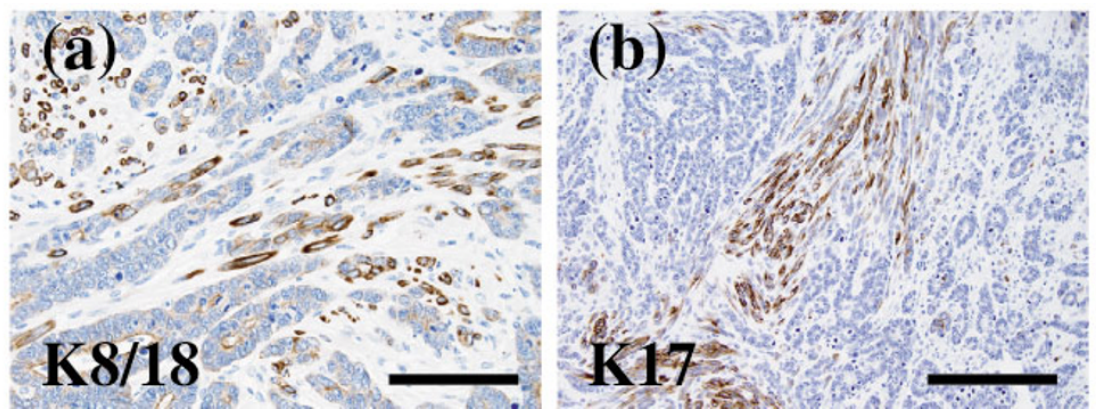

Epithelial to mesenchymal transition (EMT) in a mouse transgenic for SV40-TAg: EMT is associated with increased expression of luminal (a) and myoepithelial (b) terminal differentiation markers. Scale bars, $80 \mu \mathrm{m}$ (a) and $160 \mu \mathrm{m}$ (b).

Carcinomas in B6SJL-Wnt1-and FBV-Wnt1-transgenic mice were essentially similar and had the classical appearance of a type $\mathrm{P}$ tumor. However, they differed slightly with regard to their proteotypic patterns: squamous differentiation and expression of $\mathrm{K} 5$ and $\mathrm{K} 8 / 18$ was higher in B6SJL-Wnt1-than in FBV-Wnt1-transgenic mice (Table 1; Fig. 11a,11b).

\section{Tumor progression}

EMT, an important morphologic marker of tumor progression [32,33], was detected in 23 tumors. It was most commonly observed in Myc-induced carcinomas although it was also identified in Hras-and in SV40-TAg-induced carcinomas, and in carcinomas spontaneously arising in SJL/J and PL/J mice. Various proportions of neoplastic cells with a mesenchymal phenotype expressed vimentin (Figs 3, 8b), K5 (Fig. 8c), K14 (Fig. 8e), and K17 (Figs 8f, 9b). These cells consistently expressed SMA but could not be differentiated from myofibroblasts on the basis of the expression of this antigen alone (Fig. 8a). EMT was also associated with increased expression of K8/18 (Figs 8d, 9a). In most cases (20 of 23), a small number of cells with a myoepithelial phenotype were present in the glandular or solid areas in the immediate vicinity of the areas of EMT (Fig. 8c,8f). 


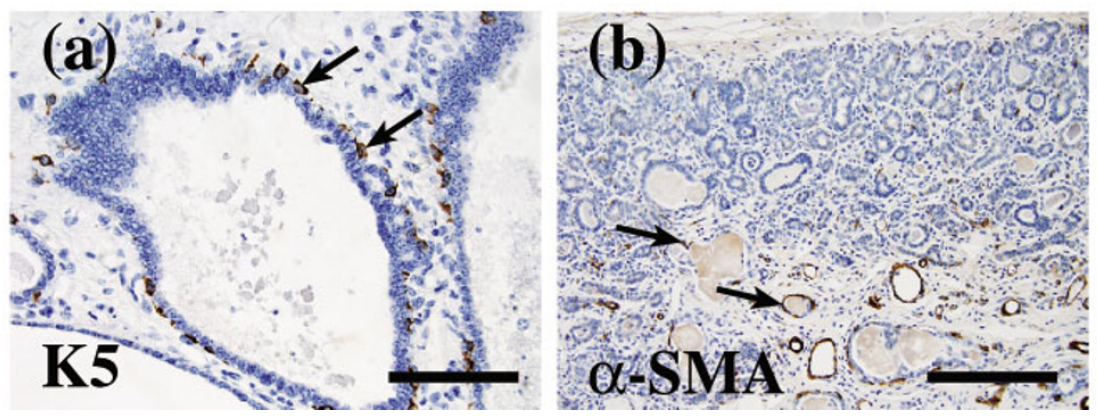

Neoplasms from Tgfa-transgenic mice: myoepithelial differentiation is present in macrocysts (a, arrows $<$ ) and in lactation-responsive plaques $(\mathbf{b}$, arrows). Scale bars, $80 \mu \mathrm{m}$ (a) and $160 \mu \mathrm{m}$ (b).

Figure 11

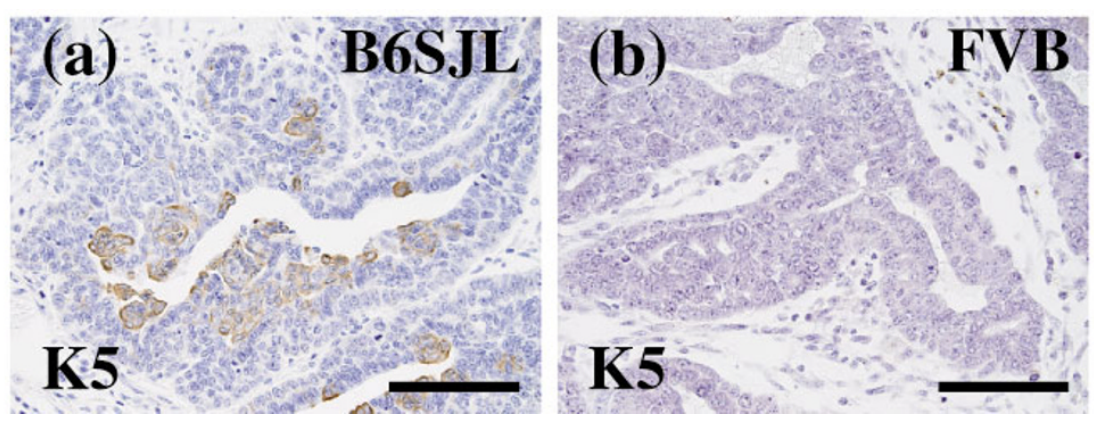

Influence of the background strain on protein expression in type $\mathrm{P}$ tumors: the expression of $\mathrm{K} 5(\mathbf{a}, \mathrm{b})$ and $\mathrm{K} 8 / 18$ (not shown) is higher, and squamous differentiation (not shown) is more prominent in B6SJL-Wnt1 than in FVB/NJ-Wnt1 mice. Scale bar, $80 \mu \mathrm{m}$.

Morphologic progression was also observed in microacinar adenocarcinomas associated with MMTV infection in $\mathrm{C} 3 \mathrm{H} /$ HeJ mice, where it was characterized by focal to multifocal acquisition of a solid pattern. Acquisition of the solid pattern was associated with a loss of immunolabeling for MMTV proteins (data not shown) by neoplastic cells, but the expression of terminal differentiation markers remained unaltered.

Neu-induced carcinomas did not display a morphologic alteration suggestive of tumor progression, although the tumors evaluated included both metastatic and non-metastatic neoplasms (data not shown). The markers tested in this study did not segregate the three cell types classically described in Neu-and Hras-induced tumors [7]. EMT was not observed in Notch4-induced carcinomas, although the glandular pattern of these neoplasms is reminiscent of Myc-and SV40-TAg-induced carcinomas.

\section{Pathway pathology}

Three histologic features of mammary tumors have recently been related to the activation of specific pathways: myoepithelial differentiation has been associated with activation of the Wnt pathway [7], squamous metaplasia has been attributed to $\beta$-catenin stabilization [34-37], and alveolar differentiation and milk secretion are dependent on signal transducer and activator of transcription 5a [38]. As expected, all Wnt1-induced carcinomas and spontaneous type $\mathrm{P}$ tumors displayed myoepithelial differentiation. In addition, myoepithelial differentiation, as assessed by routine H\&E histology or immunohistochemistry, was identified in spontaneous papillary carcinomas with a bi-stratified epithelium, MMTV-associated microacinar carcinomas, adenomyoepitheliomas, and adenosquamous carcinomas.

Squamous metaplasia associated with expression of the full array of terminal differentiation markers of the suprabasal layers of the epidermis was found only in adenosquamous carcinomas (Fig. 6a,6b,6c,6d,6e,6f,6g,6h,6i). However, squamous metaplasia was also identified in some MMTV-associated (7 of 9) and Wnt1-induced (12 of 13) type $P$ tumors, Myc-induced carcinomas ( 7 of 19$)$, adenomyoepitheliomas (3 of 5), and spontaneous carcinomas exhibiting EMT (1 of 4). In spite of areas histologically consistent with squamous differentiation, MMTV-associated and transgene-induced type $\mathrm{P}$ tumors express only a limited set of suprabasal markers of the epidermis (Table 1). For example, $\mathrm{K} 1$ and $\mathrm{K} 10$, two markers of the stratum 


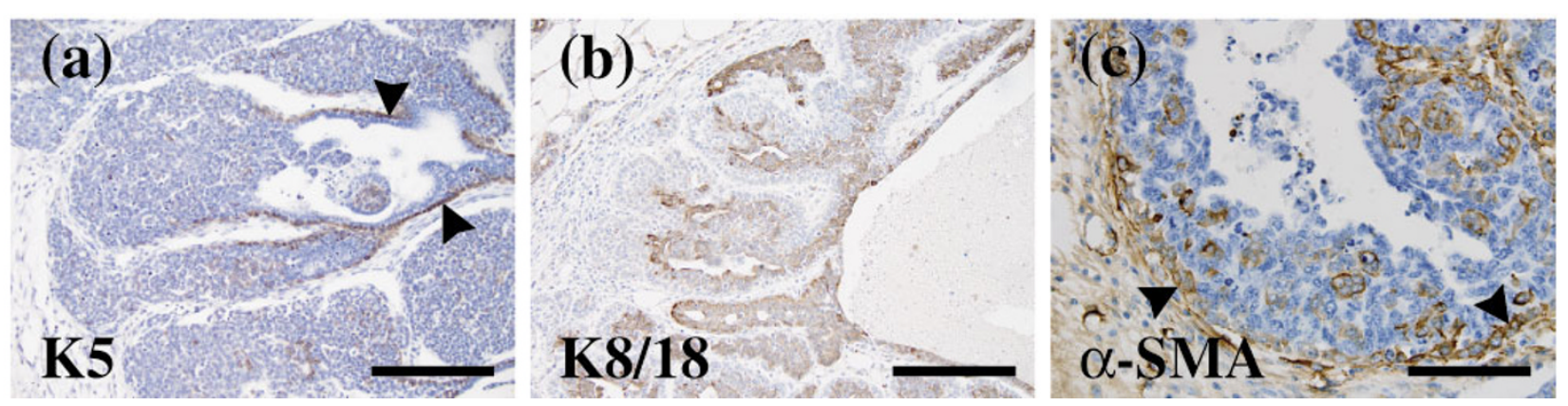

Type $\mathrm{P}$ tumors arise in mice infected by the mouse mammary tumor virus. Myoepithelial differentiation is prominent in ductal areas (a, arrowheads), whereas suprabasal cells have a luminal phenotype and label for K8/18 (b). Clusters and individual suprabasal cells are labeled by antibodies against $\alpha$-smooth muscle actin (c) and in cells with myoepithelial differentiation (arrowheads). Scale bars, $320 \mu \mathrm{m}$ (a), $160 \mu \mathrm{m}$ (b) and $80 \mu \mathrm{m}$ (c).

spinosum, were seldom expressed (4 of 30 and 6 of 30 carcinomas, respectively) in neoplasms other than adenosquamous carcinomas that exhibited cornification, whereas involucrin, a marker of the stratum corneum, was expressed in 19 of 30 such neoplasms.

\section{Discussion}

In the present study, interpretation of immunohistochemistry results determined the following: first, that expression of terminal differentiation markers categorizes spontaneous and transgenic models of mammary neoplasia into 'simple' carcinomas, 'complex' carcinomas, and carcinomas with EMT; second, that most neoplasms are composed of multiple cell populations; and third, that some transgenic and spontaneous neoplasms are histologically and immunohistochemically indistinguishable, and they provide an opportunity to test the hypothesis that tumor phenotype predicts tumor genotype $[6,7]$.

\section{Proteotypic patterns: luminal, luminal/myoepithelial, and luminal with EMT}

Like human breast tumors [14], most mouse mammary tumors are exclusively composed of neoplastic cells with a luminal phenotype, suggesting that they developed from a progenitor cell committed to the luminal lineage. Progression to EMT through a myoepithelial stage was observed in Myc-, Hras-, and SV40-TAg-induced carcinomas, a subset of spontaneous mammary carcinomas in $\mathrm{PL} / \mathrm{J}$ and $\mathrm{SJL} / \mathrm{J}$ mice, and has also been reported in mice transgenic for Tgfa [39] and matrix metalloproteinase 3 [40]. Three major pathways have been implicated in EMT: the pathway controlled by the activation of Hras and Src, the transforming growth factor $\beta$ pathway, and the Wnt pathway [32]. Evaluation of the expression of target genes of each of these pathways is needed to determine the molecular mechanisms associated with EMT in mouse models of mammary carcinogenesis.
Type $\mathrm{P}$ tumors and microacinar carcinomas constitutively express myoepithelial markers, whereas expression of these markers is an indicator of progression in Myc-, Hras, and SV40-TAg-induced carcinomas, as it is in some types of human breast cancer $[4,15,41]$. As a consequence, misinterpretations are likely to occur if tumors are evaluated for EMT with whole-tumor methodologies such as gene or protein array technologies.

The genetic background of transgenic mouse models of mammary tumors might account for differences in the penetrance, latency, and phenotype of mammary proliferating lesions [42-44]. The histological phenotype of tumors arising in Wnt1-transgenic mice was similar, regardless of the background. However, the background strain influenced the proteotypic pattern of these tumors. This observation emphasizes the importance of the background strain in genetically engineered mice, suggests the presence of tumor modifier genes, and indicates possible similar differences in humans.

\section{Cell populations}

The presence of cells negative or weakly positive for terminal differentiation markers establishes the presence of compartments of less differentiated cells in specific types of mammary carcinomas. This observation supports the hypothesis that undifferentiated cells, so-called 'mammary stem' cells, are the source of mammary tumors $[45,46]$. The histologic phenotype and the proteotypic pattern of type $P$ tumors constitutes the most striking evidence for this hypothesis: the fronds in these carcinomas caricatured terminal end buds of the pubertal mammary gland, one of the compartments in which mammary stem cells are found $[47,48]$. Gene array data also support a stem cell origin for neoplasms arising in mice transgenic for Wnt1 [13]. In adenomyoepitheliomas and adenosquamous carcinomas, the location of cells that did not express terminal differentiation markers is suggestive of a ductal origin for these neo- 
plasms. Interestingly, a second compartment of mammary stem cells is located in ductal suprabasal cells [49].

In addition to viable cells, a large proportion of neoplasms contained areas of cornification and necrosis. This heterogeneous group of non-viable cells has recently been named 'non-tumorigenic cancer cells' [50]. These cells need to be differentiated from neoplastic cells with selfrenewal potential, including those cells with invasive or metastatic potential. Because the populations of 'non-tumorigenic cancer cells' might account for a significant proportion of some neoplasms, they might interfere with studies aiming at evaluating RNA or protein expression or genetic damage at the whole-tumor level.

\section{Pathway pathology}

Cardiff and colleagues [6] initially proposed that tumor architecture and terminal differentiation markers can predict tumor genotype. The concept has subsequently been refined [7] and is supported by molecular data [12,13,51]. The present study confirmed that simple carcinomas with a solid pattern are typical of tumors driven by the $\mathrm{Neu}$ and Ras pathways, whereas type $\mathrm{P}$ tumors are a feature of neoplasms arising in mice transgenic for Wnt1. That type $P$ tumors are also found in MMTV-infected mice was expected because Wnt1 is activated in $75 \%$ of mammary carcinomas arising in $\mathrm{C} 3 \mathrm{H} / \mathrm{HeJ}$ mice [52], and this observation supports the validity of the pathway pathology hypothesis.

Although promising, the pathology pathway concept has some limitations that are illustrated by our data. For example, Myc-induced carcinomas express large amounts of whey acidic protein and casein $\beta$ [53], which should correlate with histologic evidence of proteinaceous secretion. However, only 5 of 20 Myc-induced carcinomas examined in this study had evidence of proteinaceous or lipid secretion. In addition, the pathology pathway concept predicts that Myc-, Hras-, and Neu-induced carcinomas should share similar pathways, distinct from those of Wnt1induced carcinomas. However, Myc-and Wnt1-induced neoplasms are independent of cyclin D1, whereas Hrasand $\mathrm{Neu}$-induced carcinomas are dependent on cyclin D1 $[12,54]$, indicating that tumor phenotype and tumor genotype are not consistently matched.

\section{Conclusions}

The observations that mammary neoplasms of mice transgenic for H-Ras, Myc, Neu, Notch4 and SV4O-Tag, and that papillary carcinomas of BALB/cJ mice are exclusively composed of cells with a luminal phenotype, are consistent with the hypothesis that these neoplasms arise from a cell committed to the luminal lineage. The fact that adenomyoepitheliomas, adenoacanthomas, microacinar carcinomas, and type $P$ tumors have a complex phenotype is consistent with a mammary stem cell origin. In addition, it is apparent that cancer progression in mammary carcinomas of mice transgenic for H-Ras, Myc, and SV4O-Tag is often associated with EMT. However, EMT does not occur in mammary tumors of mice transgenic for Tgfa, Neu, Notch4, and Wnt1, which indicates that the morphologic features associated with cancer progression are determined by the initiating oncogenic events.

\section{Competing interests}

The authors declare that they have no competing interests.

\section{Acknowledgements}

We thank CM Conley, HJ Miller, J Miller, EF Taylor, and SL Williamson for technical assistance. We are grateful to RT Bronson, TV Golovkina, and BA Richards-Smith for critical review of the manuscript. This study was supported in part by National Institutes of Health grants CA34196, CA88327, CA89713, and RR173.

\section{References}

1. Bloodgood JC: Encapsulated and non-encapsulated cystic adenomata observed from 1890 to 1931. Am J Cancer 1932, 16:103-176.

2. Perou CM, Jeffrey SS, van de Rijn M, Rees CA, Eisen MB, Ross DT, Pergamenschikov A, Williams CF, Zhu SX, Lee JC, et al:: Distinctive gene expression patterns in human mammary epithelial cells and breast cancers. Proc Natl Acad Sci USA 1999, 96:9212-9217.

3. Sorlie T, Perou CM, Tibshirani R, Aas T, Geisler S, Johnsen H, Hastie T, Eisen MB, van de Rijn M, Jeffrey SS, et al.: Gene expression patterns of breast carcinomas distinguish tumor subclasses with clinical implications. Proc Natl Acad Sci USA 2001, 98:10869-10874.

4. van de Rijn M, Perou CM, Tibshirani R, Haas $\mathrm{P}$, Kallioniemi $\mathrm{O}$, Kononen J, Torhorst J, Sauter G, Zuber M, Kochli OR, et al: Expression of cytokeratins 17 and 5 identifies a group of breast carcinomas with poor clinical outcome. $\mathrm{Am} J$ Pathol 2002, 161:1991-1996.

5. Rosen PP, Oberman HA: Tumors of the Mammary Gland Washington, DC: Armed Forces Institute of Pathology; 1992.

6. Cardiff RD, Sinn E, Muller W, Leder P: Transgenic oncogene mice. Tumor phenotype predicts genotype. Am J Pathol 1991, 139:495-501.

7. Rosner A, Miyoshi K, Landesman-Bollag E, Xu X, Seldin DC, Moser AR, MacLeod CL, Shyamala G, Gillgrass AE, Cardiff RD: Pathway pathology: histological differences between $\mathrm{ErbB} / \mathrm{Ras}$ and Wnt pathway transgenic mammary tumors. Am J Pathol 2002, 161:1087-1097.

8. Bocker W, Bier B, Freytag G, Brommelkamp B, Jarasch ED, Edel G, Dockhorn-Dworniczak B, Schmid KW: An immunohistochemical study of the breast using antibodies to basal and luminal keratins, alpha-smooth muscle actin, vimentin, collagen IV and laminin. Part II: Epitheliosis and ductal carcinoma in situ. Virchows Arch A Pathol Anat Histopathol 1992, 421:323-330.

9. Joshi MG, Lee AK, Pedersen CA, Schnitt S, Camus MG, Hughes $\mathrm{KS}$ : The role of immunocytochemical markers in the differential diagnosis of proliferative and neoplastic lesions of the breast. Mod Pathol 1996, 9:57-62.

10. Malzahn K, Mitze M, Thoenes M, Moll R: Biological and prognostic significance of stratified epithelial cytokeratins in infiltrating ductal breast carcinomas. Virchows Arch 1998, 433:119-129.

11. Alizadeh AA, Ross DT, Perou CM, van de Rijn M: Towards a novel classification of human malignancies based on gene expression patterns. J Pathol 2001, 195:41-52.

12. Desai KV, Xiao N, Wang W, Gangi L, Greene J, Powell Jl, Dickson $\mathrm{R}$, Furth $\mathrm{P}$, Hunter K, Kucherlapati R, et al.: Initiating oncogenic event determines gene-expression patterns of human breast cancer models. Proc Natl Acad Sci USA 2002, 99:6967-6972.

13. Li Y, Welm B, Podsypanina K, Huang S, Chamorro M, Zhang X Rowlands T, Egeblad M, Cowin P, Werb Z, et al.: Evidence that 
transgenes encoding components of the Wnt signaling pathway preferentially induce mammary cancers from progenitor cells. Proc Natl Acad Sci USA 2003, 100:15853-15858.

14. Sorlie T, Tibshirani R, Parker J, Hastie T, Marron JS, Nobel A, Deng $\mathrm{S}$, Johnsen H, Pesich R, Geisler S, et al.: Repeated observation of breast tumor subtypes in independent gene expression data sets. Proc Natl Acad Sci USA 2003, 100:8418-8423.

15. Tsuda H, Takarabe T, Hasegawa T, Murata T, Hirohashi S: Myoepithelial differentiation in high-grade invasive ductal carcinomas with large central acellular zones. Hum Pathol 1999, 30:1134-1139.

16. Cardiff RD: The biology of mammary transgenes: five rules. $J$ Mammary Gland Biol Neoplasia 1996, 1:61-73.

17. Cardiff RD, Anver MR, Gusterson BA, Hennighausen L, Jensen RA, Merino MJ, Rehm S, Russo J, Tavassoli FA, Wakefield LM, et al.: The mammary pathology of genetically engineered mice: the consensus report and recommendations from the Annapolis meeting. Oncogene 2000, 19:968-988.

18. Cardiff RD: Validity of mouse mammary tumour models for human breast cancer: comparative pathology. Microsc Res Tech 2001, 52:224-230.

19. Cardiff RD, Wagner U, Henninghausen L: Mammary cancer in humans and mice: a tutorial for comparative pathology. Vet Pathol 2001, 38:357-358.

20. Sundberg BA, Sundberg JP: Medical record keeping for project analysis. In Systematic approach to evaluation of mouse mutations Edited by: Sundberg JP, Boggess D. Boca Raton: CRC Press; 2000:47-55.

21. Foulds L: The histological analysis of neoplasms. In Neoplastic development Edited by: Foulds L. London: Academic Press; 1969:137-217

22. Rose-Hellekant TA, Sandgren EP: Transforming growth factor alpha-and c-myc-induced mammary carcinogenesis in transgenic mice. Oncogene 2000, 19:1092-1096.

23. van Nie R, Dux A: Biological and morphological characteristics of mammary tumors in GR mice. J Natl Cancer Inst 1971, 46:885-897.

24. McGowan KM, Coulombe PA: Onset of keratin 17 expression coincides with the definition of major epithelial lineages during skin development. J Cell Biol 1998, 143:469-486.

25. Mikaelian I, Nanney LB, Parman KS, Kusewitt DF, Ward JM, Näf D, Krupke DM, Eppig JT, Bult C, Seymour R, et al.: Antibodies that label paraffin-embedded mouse tissues: a collaborative endeavor. Toxicol Pathol 2004, 32:170-181.

26. Skalli O, Ropraz P, Trzeciak A, Benzonana G, Gillessen D, Gabbiani G: A monoclonal antibody against alpha-smooth muscle actin: a new probe for smooth muscle differentiation. $J$ Cell Biol 1986, 103:2787-2796.

27. Purdy A, Case L, Duvall M, Overstrom-Coleman M, Monnier N, Chervonsky A, Golovkina T: Unique resistance of $\mathrm{I} / \mathrm{LnJ}$ mice to a retrovirus is due to sustained interferon gamma-dependent production of virus-neutralizing antibodies. J Exp Med 2003, 197:233-243

28. Näf D, Krupke DM, Sundberg JP, Eppig JT, Bult CJ: The Mouse Tumor Biology Database: a public resource for cancer genetics and pathology of the mouse. Cancer Res 2002, 62:1235-1240.

29. Mikaelian I, Hovick M, Silva KA, Burzenski LM, Shultz LD, Cox GA, Sundberg JP: Expression of terminal differentiation proteins define stages of mouse mammary gland development. Vet Pathol in press.

30. Hampe JF, Misdorp W: Tumours and dysplasias of the mammary gland. Bull World Health Organ 1974, 50:111-133.

31. Sundberg JP, Hanson CA, Roop DR, Brown KS, Bedigian HG: Myoepitheliomas in inbred laboratory mice. Vet Pathol 1991, 28:313-323.

32. Savagner $P$ : Leaving the neighborhood: molecular mechanisms involved during epithelial-mesenchymal transition. Bioessays 2001, 23:912-923.

33. Tosh D, Slack JM: How cells change their phenotype. Nat Rev Mol Cell Biol 2002 3:187-194.

34. Michaelson JS, Leder P: $\beta$-catenin is a downstream effector of Wnt-mediated tumorigenesis in the mammary gland. Oncogene 2001, 20:5093-5099.

35. Miyoshi K, Rosner A, Nozawa M, Byrd C, Morgan F, LandesmanBollag E, Xu X, Seldin DC, Schmidt EV, Taketo MM, et al: Activation of different Wnt/beta-catenin signaling components in mammary epithelium induces transdifferentiation and the formation of pilar tumors. Oncogene 2002, 21:5548-5556.

36. Miyoshi K, Shillingford JM, Le Provost F, Gounari F, Bronson R, von Boehmer H, Taketo MM, Cardiff RD, Hennighausen L, Khazaie K: Activation of $\beta$-catenin signaling in differentiated mammary secretory cells induces transdifferentiation into epidermis and squamous metaplasias. Proc Natl Acad Sci USA 2002, 99:219-224.

37. Renou JP, Bierie B, Miyoshi K, Cui Y, Djiane J, Reichenstein M Shani M, Hennighausen L: Identification of genes differentially expressed in mouse mammary epithelium transformed by an activated beta-catenin. Oncogene 2003, 22:4594-4610.

38. Liu X, Robinson GW, Wagner KU, Garrett L, Wynshaw-Boris A Hennighausen L: Stat5a is mandatory for adult mammary gland development and lactogenesis. Genes Dev 1997, 11:179-186.

39. Gorska AE, Jensen RA, Shyr Y, Aakre ME, Bhowmick NA, Moses HL: Transgenic mice expressing a dominant-negative mutant type II transforming growth factor-beta receptor exhibit impaired mammary development and enhanced mammary tumor formation. Am J Pathol 2003, 163:1539-1549.

40. Sternlicht MD, Lochter A, Sympson CJ, Huey B, Rougier JP, Gray JW, Pinkel D, Bissell MJ, Werb Z: The stromal proteinase MMP3/stromelysin-1 promotes mammary carcinogenesis. Cell 1999, 98:137-146.

41. Tsuda H, Takarabe T, Hasegawa F, Fukutomi T, Hirohashi S: Large, central acellular zones indicating myoepithelial tumor differentiation in high-grade invasive ductal carcinomas as markers of predisposition to lung and brain metastases. $A m$ Surg Patho/ 2000, 24:197-202.

42. Moser AR, Hegge LF, Cardiff RD: Genetic background affects susceptibility to mammary hyperplasias and carcinomas in Apc(min)/+ mice. Cancer Res 2001, 61:3480-3485.

43. Nielsen LL, Gurnani M, Catino JJ, Tyler RD: In wap-ras transgenic mice, tumor phenotype but not cyclophosphamide-sensitivity is affected by genetic background. Anticancer Res 1995 , 15:385-392

44. Rose-Hellekant TA, Gilchrist K, Sandgren EP: Strain background alters mammary gland lesion phenotype in transforming growth factor-alpha transgenic mice. Am J Pathol 2002, 161:1439-1447.

45. Pierce GB, Nakane PK, Martinez-Hernandez A, Ward JM: Ultrastructural comparison of differentiation of stem cells of murine adenocarcinomas of colon and breast with their normal counterparts. J Natl Cancer Inst 1977, 58:1329-1345

46. Reya T, Morrison SJ, Clarke MF, Weissman IL: Stem cells, cancer, and cancer stem cells. Nature 2001, 414:105-111.

47. Chepko G, Smith GH: Three division-competent, structurallydistinct cell populations contribute to murine mammary epithelial renewal. Tissue Cell 1997, 29:239-253.

48. Kenney NJ, Smith GH, Lawrence E, Barrett JC, Salomon DS: Identification of stem cell units in the terminal end bud and duct of the mouse mammary gland. J Biomed Biotechnol 2001, 1:133-143.

49. Smith $\mathrm{GH}$, Medina D: A morphologically distinct candidate for an epithelial stem cell in mouse mammary gland. $J \mathrm{Cell} \mathrm{Sci}$ 1988, 90(Pt 1):173-183.

50. Dontu G, Al-Haji M, Abdallah WM, Clarke MF, Wicha MS: Stem cells in normal breast development and breast cancer. Cell Prolif 2003, 36(Suppl 1):59-72.

51. Morrison BW, Leder P: neu and ras initiate murine mammary tumors that share genetic markers generally absent in c-myc and int-2-initiated tumors. Oncogene 1994, 9:3417-3426.

52. Callahan R, Smith GH: MMTV-induced mammary tumorigenesis: gene discovery, progression to malignancy and cellular pathways. Oncogene 2000, 19:992-1001.

53. Schoenenberger CA, Andres AC, Groner B, van der Valk M, LeMeur M, Gerlinger P: Targeted c-myc gene expression in mammary glands of transgenic mice induces mammary tumours with constitutive milk protein gene transcription. $E M B O$ J 1988, 7:169-175

54. Yu Q, Geng Y, Sicinski P: Specific protection against breast cancers by cyclin D1 ablation. Nature 2001, 411:1017-1021. 